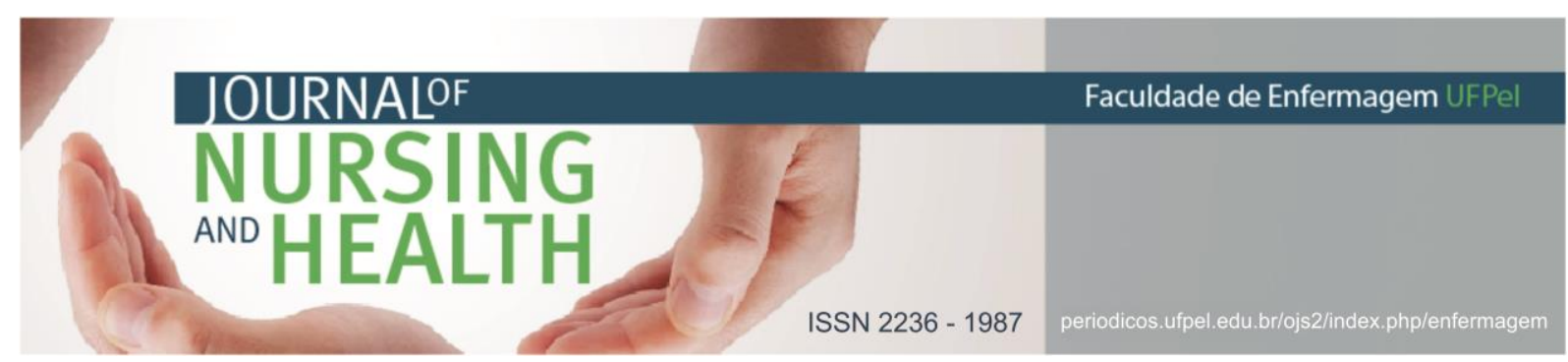

ENTREVISTA NARRATIVA

\title{
Sobre os caminhos do primeiro grupo de ouvidores de vozes no Brasil
}

\author{
On the paths of the first group of voice hearers in Brazil
}

Sobre los caminos del primer grupo de oyentes de voces en Brasil

Coimbra, Valéria Christteloํㅜ Bretanha, Andréia Ferreira²; Rodrigues, Cândida Garcia Sinott Silveira ${ }^{3}$

Como citar este artigo: Coimbra VCC, Bretanha AF, Rodrigues CGS. Sobre os caminhos do primeiro grupo de ouvidores de vozes no Brasil. J. nurs. health. 2018;8(n.esp.):e188421

Descritores: Saúde mental; Narração; Relato de caso.

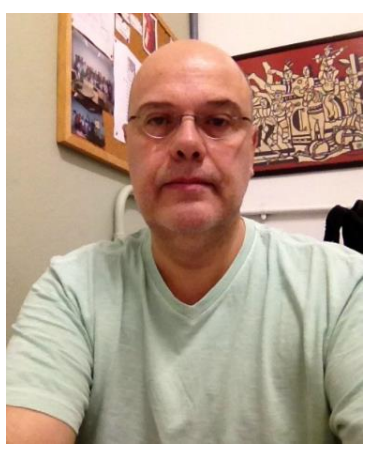

APRESENTAÇÃO

Esta narrativa conta parte da história de Octavio Domont de Serpa Júnior, 56 anos, médico psiquiatra e professor associado do Instituto de Psiquiatria da Universidade Federal do Rio de Janeiro (IPUB-UFRJ).

\section{A história de Octavio}

Octavio Domont de Serpa Júnior aproximou-se por acaso do tema “ouvidores de vozes" quando atuava como médico no hospital dia Casa Verde, no final dos anos 90. Nessa ocasião ele não tinha a menor ideia de que existia a Intervoice e nem ao menos sabia quem era Marius Romme. Foi então que um usuário do hospital the reclamou da inexistência de um espaço onde ele pudesse falar das vozes que ouvia. Existiam várias oficinas, entretanto nenhuma que se dedicasse especificamente a ouvir as experiências dos ouvidores de vozes. Rapidamente este usuário foi apoiado pelos demais que igualmente, relatavam ouvir vozes e partilhavam da mesma necessidade.

Após o relato dos usuários, foi criada uma oficina, que por indicação, passou a ser chamada "Oficina de Vozes", experiência que foi acompanhada por Octavio Domont de Serpa Júnior por alguns anos e que o encantou justamente pela

1 Enfermeira. Doutora em Enfermagem. Universidade Federal de Pelotas (UFPEL). E-mail: valeriacoimbra@hotmail.com http://orcid.org/0000-0001-5327-0141

2 Enfermeira. Mestre em Ciências. Universidade Federal de Pelotas (UFPEL). E-mail: andreiabretanha@hotmail.com http://orcid.org/0000-0002-4579-4903

3 Enfermeira. Mestre em Ciências. Universidade Federal de Pelotas (UFPEL). E-mail: candidasinott@hotmail.com http://orcid.org/0000-0001-7719-0621 


\section{NURSING \\ AND \\ HEALTH \\ ISSN $2236-1987$}

possibilidade de participar de um grupo onde usuários externavam suas histórias de como viviam na presença das vozes.

Entre 1998 e 2000, foram muitas participações nos grupos e oficinas sobre a temática, entretanto, na época, Octavio Domont de Serpa Júnior não tinha ideia da diversidade de experiências que nasciam naquele espaço e da possibilidade de dar sentido a elas.

Dois anos após a primeira aproximação com o tema, em uma época em que a internet ainda engatinhava e não havia website de Intervoice, por acaso, em uma livraria em Copacabana no Rio de Janeiro, Octavio Domont de Serpa Júnior encontrou a tradução portuguesa do livro de Marius Romme "Na companhia das vozes", e por entender que tinha tudo a ver com o que estava vivendo no momento, leu o livro obstinadamente, familiarizando-se com o assunto e buscando contato com outras pessoas que trabalhavam com o mesmo tema.

A Oficina de Vozes foi acompanhada por Octavio até 2002, quando ele se desligou do hospital dia Casa Verde, mas continuou em atividade, acompanhada por outros profissionais.

\section{A trajetória do grupo}

Em 2002, o médico, agora docente concursado do Instituto de Psiquiatria da UFRJ, cria o Laboratório de estudos e pesquisas em Psicopatologia e Subjetividade, cujo interesse é conhecer a experiência de adoecimento psíquico através de narrativas. Neste contexto, em parceria com mais duas pesquisadoras, Erotildes Maria Leal e Núria Malajovich Muñoz, o grupo de ouvidores de vozes é retomado em 2004, no Centro de Atenção Diária da UFRJ (CAD-IPUB), aliando pesquisa e intervenção clínica sobre o assunto. Simultaneamente, Núria Malajovich Muñoz, que estava realizando seu doutorado e atuava em um Centro de Atenção Psicossocial (CAPS) na cidade do Rio de Janeiro, iniciou também uma oficina de vozes neste serviço, reunindo muitos materiais que acabaram por dar origem, mais tarde, a um artigo.

Em 2006, Octavio viaja a Paris para fazer um pós-doutorado em metodologias da primeira pessoa, fato que acabou por afastá-lo do grupo, restando destas experiências, produções acadêmicas e um manual para grupos de ouvidores de vozes, praticamente pronto, mas que não saiu do papel. 0 manual, inédito, falava das experiências vividas nas oficinas de vozes, uma revisão teórica e uma reflexão sobre o trabalho com grupo.

O grupo do CAD-IPUB continuou por mais alguns anos, moderado por profissionais do próprio serviço que já participavam do grupo desde o seu início.

Eis que no início de 2015, por convite de Pablo Valente, diretor do Centro Nacional de Novas Abordagens Terapêuticas (CENAT), o IPUB-UFRJ sediou o I Fórum sobre Novas Abordagens em Saúde Mental no estado do Rio de Janeiro, e foi o momento oportuno para que Octávio Domont de Serpa Júnior conhecesse Marius Romme, que já estava no Brasil para participar de outro fórum e acabou reaquecendo 


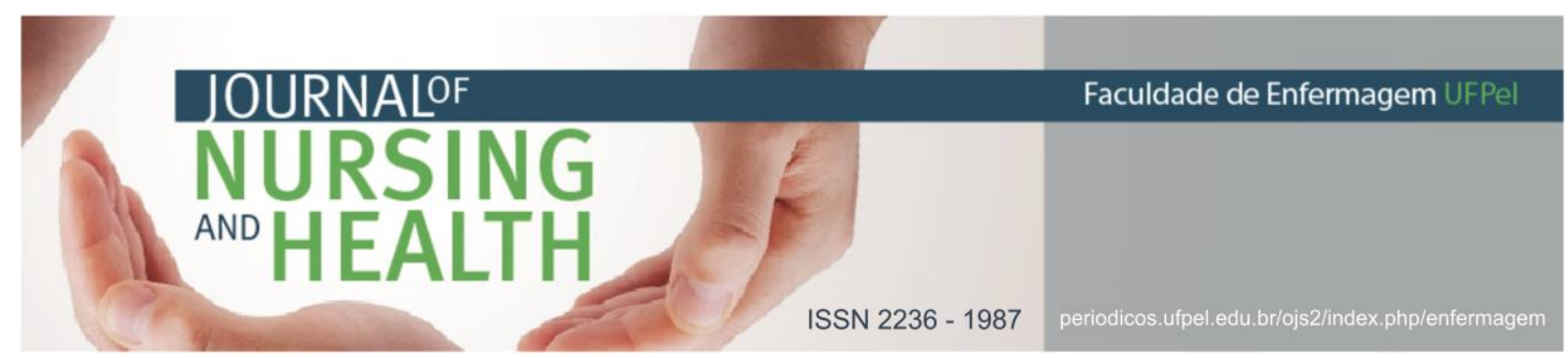

as discussões a respeito do tema, através de uma conferência que falava sobre a experiência de ouvir vozes, e Paul Baker, que participou do Fórum.

Após a vinda de Marius Romme e Paul Baker, Octavia Cristina Barros, que estava desenvolvendo sua pesquisa de mestrado sob orientação do prof. Octavio Domont de Serpa Júnior, tendo como tema de estudo os ambientes virtuais para ajuda mútua de ouvidores de vozes, se anima, em parceria com o prof. Octavio e o terapeuta ocupacional Abmael de Sousa Alves, do CAD-IPUB, a reiniciar o grupo, cujas atividades tinham sido interrompidas alguns anos antes. Atualmente o grupo continua em atividade, toda quinta-feira às 14 horas, acompanhado por Abmael de Sousa Alves.

\section{Desafios atuais}

Para Octavio Domont de Serpa Júnior, há necessidade de se conhecer a experiência de ouvidores de vozes fora do cenário psiquiátrico, pois ele acredita que - Instituto carrega uma carga da cultura hospitalar, psiquiátrica, uma face biomédica muito marcada e relações hierarquizadas. Ele nos fala que seria interessante perceber como a experiência é contada fora do ambiente psiquiátrico, na comunidade e conduzida pelos próprios usuários. Estes fatos iriam acrescentar às experiências vividas aos Centros de Atenção Psicossociais. Mas enfim, declara que esta é uma tarefa para os que virão. No momento, seus desafios, embora próximos do tema, seguem outro caminho, o da pesquisa de metodologias e práticas que possam potencializar a construção de narrativas por parte de quem vive a experiência de ouvir vozes e outras formas de sofrimento psíquico e a forma como podem ser aplicadas nos processos formativos de profissionais de saúde mental. 